\title{
STUDY ON THE DESIGN OF HEATING AND ENERGY SAVING OF ENCLOSURE STRUCTURE OF RURAL SELF-BUILT HOUSES
}

\author{
Weixian Chang ${ }^{1}$ and Hui Dong ${ }^{2}$
}

\author{
1. Shangluo Vocational and Technical College, Shangluo, Shaanxi 726000, China; \\ changche3483@yeah.net \\ 2. Forestry College of Inner Mongolia Agricultural University, Hohhot, Inner \\ Mongolia 010051, China
}

\begin{abstract}
For severe cold areas, indoor heating in winter is very important, and it is also important to achieve energy saving and emission reduction in the heating process. This paper briefly introduced a kind of heating envelope structure, the geothermal energy-based phase change wall, and analyzed two rural self-built houses in Shangluo city, Shaanxi province. One self-built house was built without the phase change wall, and the other was built with the geothermal energy-based phase change wall by the municipal government. The results showed that the self-built house that adopted the phase change wall had a better heat preservation effect and relieved the indoor temperature fluctuation; after the heating equipment was turned on, the self-built house that adopted the geothermal energy-based phase change wall had a higher and more stable indoor temperature, and the power consumption during the experiment was less.
\end{abstract}

\section{KEYWORDS}

Self-built house, Heating, Enclosure structure, Phase change wall

\section{INTRODUCTION}

The rapid development of the economy promotes the further development of cities and also drives the development of rural areas under the radiation of economic development, making rural areas develop in the direction of urbanization [1]. The acceleration of rural urbanization is not only reflected in the increase of the types of goods that can be purchased but also in the design of buildings. Different from the commercial housing series built by various real estate developers in big cities, rural houses are usually built on the homestead by the construction team, according to the experience. Although rural houses can meet the conventional living needs, the energy-saving need is usually not considered [2]. In the face of high temperatures in summer and low temperatures in winter, in order to make the living environment more comfortable, self-built housing residents will use equipment such as an air conditioner to adjust the indoor temperature environment. Air conditioning equipment will consume energy in the process of use, which is not conducive to sustainable development. Therefore, self-built houses not only need to meet the needs of conventional comfortable living but also meet the needs of energy-saving. Taking winter heating as an example, heating energy consumption accounts for a considerable proportion of building energy consumption. Part of the building heat comes from solar radiation, but the sunshine intensity in winter is relatively low, and the time is limited. Additional heat that comes from coal stoves, air conditioners, heating 


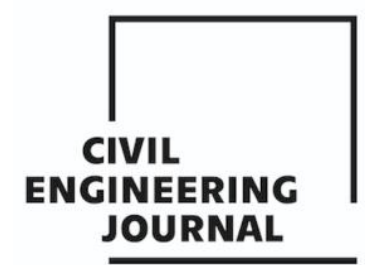

Article no. 44

THE CIVIL ENGINEERING JOURNAL 2-2021

radiators, etc. is needed to meet indoor comfort [3]. However, the above equipment will consume a lot of energy in the process of use, and the use of coal stoves is dangerous; moreover, reducing the use of heating equipment for the sake of energy consumption will reduce the indoor comfort. A good solution to the above situations is to improve the material and structure of the enclosure to enhance the heat insulation capacity, reduce the loss of indoor heat, and maintain the stability of comfort under low energy consumption. Petrichenko et al. [4] defined the influence of external temperature fluctuation on the temperature of the enclosure structure, gave a selection of the best energy-saving heating system, defined the thickness of the penetrating layer of the temperature wave, and solved and analyzed the Fourier differential equation of solid heat conduction process. Feng et al. [5] analyzed the influence of thermal characteristics of the enclosure structure on the indoor thermal environment and building thermal stability, evaluated the practicability of existing energy-saving methods of building envelope from the aspects of energy-saving effect, safety, reliability, practicability, and economy, and proposed the climatic-suitable thermal design and structure type of the envelope. Kong et al. [6] proposed a coupling strategy of hourly computational fluid dynamics simulation of indoor airflow and dynamic building energy simulation of heat transfer of the building envelope based on real-time information exchange and carried out a joint simulation of an office room with a ventilating and radiant floor cooling system. The results showed that the dynamic heat transfer characteristics of the outdoor wall and indoor air changed with the change of outdoor weather conditions. This paper briefly introduced a geothermal energy-based phase change wall heating envelope and analyzed two rural self-built houses in Shangluo city, Shaanxi province, China. One was built by villagers without the phase change wall, and the other was built with the geothermal energy-based phase change wall by the municipal government.

\section{THE GEOTHERMAL ENERGY-BASED PHASE CHANGE WALL HEATING ENVELOPE}

Compared with the commercial houses with unified specifications on different floors built by real estate developers in cities, most of the houses in rural areas are self-built. The building style of self-built houses is decided by the residents themselves, which is relatively free. However, in the process of construction, the construction workers generally will not get more scientific guidance, and the construction will be carried out according to the past construction experience. Self-built houses can meet conventional living needs, but there is no strict requirement for energy saving [7]. In the low-temperature environment in winter, the indoor residents need enough heating to maintain the indoor temperature and comfort. The most basic heating comes from sunlight, but the sunshine time is short in winter. Even if the building orientation is adjusted to receive the light as much as possible, it is difficult to maintain the whole-day heating. In order to maintain the indoor temperature, in addition to sunshine, additional heat sources are needed for heating. The relatively primitive way is to obtain heat by burning wood or fossil fuel, but this kind of heating method is dangerous in relatively closed rooms. With the popularization of electric power, relatively safer electric heating (electric furnace, air conditioner, etc.) has been gradually applied in winter, but the consumption of electric power will also increase the consumption of fossil energy, which is not conducive to sustainable development [8]. In order to achieve energy-saving and emission reduction in the process of building heating, we can start from supplying heat and preserving heat. In the aspect of supplying heat, we can upgrade the technology of heating equipment, including improving the efficiency of electric heating conversion and the intelligent level of operation. In short, the purpose is to provide enough heating with as little energy consumption as possible or use clean energy for heating. Preserving heat should focus on the structure and materials of the building, i.e., enhancing the heat insulation of the building envelope to reduce the indoor heat loss and ensure limited heat to maintain a comfortable temperature as long as possible. This paper mainly analyzed the design of the building envelope in heating energy saving. 


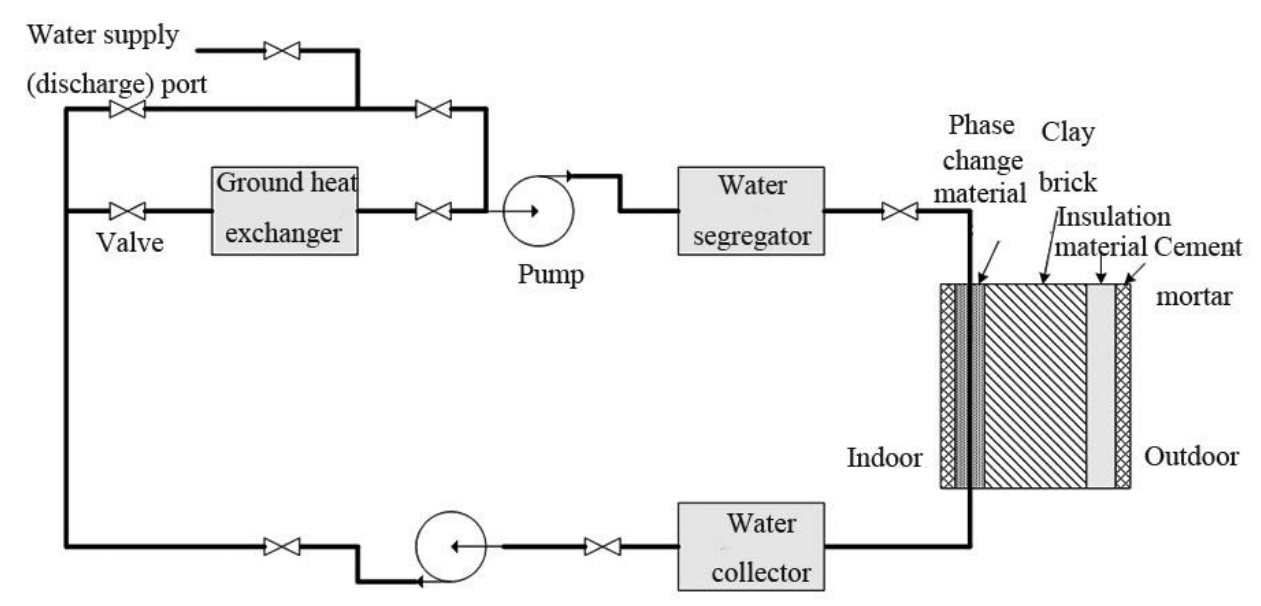

Fig. 1 - The basic structure of the geothermal energy-based phase change wall system

The envelope structure of a self-built house includes a roof, doors, windows, and walls. The wall has the largest contact area with the external environment; therefore, the overall thermal insulation of the building can be improved by strengthening the thermal insulation performance of the wall. In recent years, the improvement of building materials has improved the thermal insulation performance of walls. This study improved the thermal insulation performance of walls from the perspective of the structure. The traditional wall structure from the outside to the inside is cement mortar, brick, cement mortar, and lime [9]. In this study, phase change materials were used to improve the structure of the traditional wall. The improved phase change wall structure and the auxiliary heating system are shown in Figure 1. The basic structure of the phase change wall includes the cement mortar layer, the insulation material layer, the clay brick layer, the phase change layer [10], and the cement mortar layer. The main function of the cement mortar layer is to protect the internal materials of the wall. The function of the insulation material layer is to use the thermal insulation performance of the insulation material to reduce the heat loss in the phase change material and clay brick. Clay brick is the main structure of the wall. The phase change material of the phase change material layer is an important part of the phase change wall to improve the insulation performance. Compared with conventional materials, the phase change material has more excellent latent heat storage performance, i.e., it can store more heat. When the indoor temperature decreases, the heat stored by phase change materials will radiate to the room as much as possible under the barrier of insulation materials.

In order to further improve the heating energy-saving effect of phase change walls, this study combined geothermal energy with phase change walls. Figure 1 shows the basic structure after the combination. Its basic principle is to realize the heat exchange between the phase change material and the ground through the water flowing in the pipeline buried in the phase change material layer [11]. Taking winter heating as an example, in the daytime, the heat in the room comes from solar radiation, and part of the heat will be absorbed by the phase change material in the phase change wall. In addition, the medium water heated by the ground heat exchanger will pass through the pipe buried in the phase change material layer by the water distributor. After the phase change material absorbs the heat, the temperature will rise. When it reaches the melting point, it will melt to absorb heat, thereby storing geothermal energy. After the heat is absorbed by the phase change material, the medium water flows back to the ground heat exchanger through the water collector for heating. Due to the absence of solar radiation at night, the ambient temperature decreases, and the phase change material in the phase change wall will release the stored heat. Due to the barrier of the insulation layer, most of the heat will be transferred indoors to maintain the indoor temperature 




Article no. 44

THE CIVIL ENGINEERING JOURNAL 2-2021

stability [12]. In addition, a temperature sensor can be set in the water outlet or phase change layer of the phase change wall. When the temperature of the phase change material is lower than the threshold, the ground heat exchanger will be turned on again, and the phase change wall will be heated by medium water. However, the phase change material can absorb more latent heat by virtue of the phase change properties, i.e., it can store more heat, which can reduce the continuous startup time of the ground heat exchanger and further reduce energy consumption.

\section{CASE ANALYSIS}

\section{Case overview}

The rural self-built houses analyzed in this paper are located in Shangluo city, Shaanxi province, China. Shaanxi Province is located in the middle of China and the middle reaches of the Yellow River. The overall terrain is high in the south and north and low in the middle, with various types of landforms. In terms of climate, Shaanxi is divided into three climatic zones: subtropical climate, warm temperate climate, and middle temperate climate from south to north [13]. On the whole, it is dry and rainless in spring, hot and rainy in summer, cool and humid in autumn, and cold and dry in winter. Shangluo city is located in the southeast of Shaanxi province and at the southern foot of Qinling Mountains and the junction of Hubei and Henan provinces. Figure 2 shows the rural self-built house for example analysis in this paper. The right picture is the self-built house built by Shangluo villagers, without adding a special thermal insulation structure, and it is a conventional enclosure structure. The left picture is the self-built house designed and planned by Shangluo municipal government, whose enclosure structure adopted the geothermal energy-based phase change wall mentioned above. The floor area and configuration of the two self-built houses used for case analysis were nearly the same. The two self-built houses were located about $1 \mathrm{~km}$ apart; thus, they were regarded as in the same weather environment.



(a) A self-built house designed and built by Shangluo municipal government

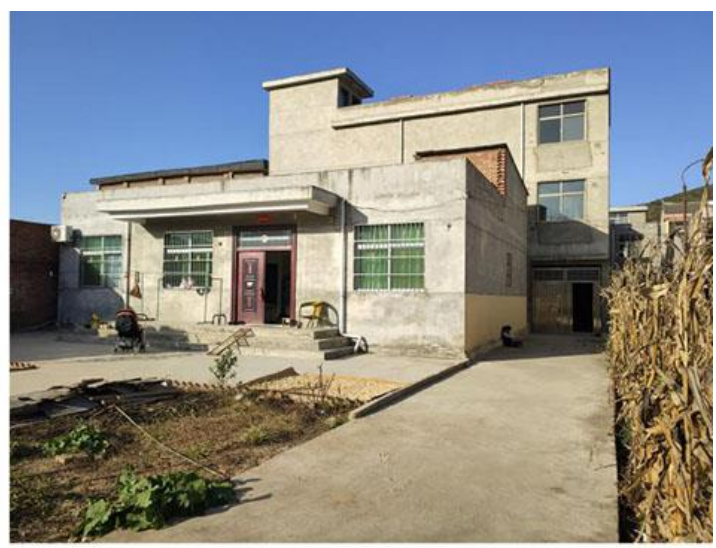

(b) A self-built house built by villagers in Shangluo

Fig. 2 - The rural self-built houses in Shangluo city

\section{Related equipment parameters}

Water - water-source heat pump main unit: there were three units; the rated heat capacity was $54 \mathrm{~kW}$, the heating input power was $7.6 \mathrm{~kW}$, the rated cooling water flow rate was $7.5 \mathrm{~m}^{3} / \mathrm{h}$, the rated refrigerant water flow rate was $12.3 \mathrm{~m}^{3} / \mathrm{h}$, and the heat pump supply and return water temperature under heating condition was $45 / 40^{\circ} \mathrm{C}$ 




Article no. 44

THE CIVIL ENGINEERING JOURNAL 2-2021

Ground heat exchanger: the ground pipe was a single U-shaped aluminum-plastic composite pipe [14], with a diameter of $25 \mathrm{~mm}$ and a length of $2.3 \mathrm{~m}$; the water demand of the ground pipe was $37.52 \mathrm{~m}^{3} / \mathrm{h}$; the pipe was embedded in parallel [15], with a borehole depth of $65 \mathrm{~m}$, a bore diameter of $100 \mathrm{~mm}$, and a distance of $2.5 \mathrm{~m}$ between the boreholes; there were 35 boreholes.

Circulating water pump: there were four circulating water pumps; the flow rate was $12 \mathrm{~m} / \mathrm{h}$, the lift was $25 \mathrm{~m}$, the rotational speed was $3000 \mathrm{r} / \mathrm{min}$, and the power was $2.0 \mathrm{~kW}$.

The doors and windows of the self-built house (a) and the self-built house (b) faced south. In terms of enclosure structure, except for the east and west walls, the materials and structural parameters of the two buildings were the same. The difference in the east and west walls between the two self-built houses was that the east and west walls of the self-built house (a) designed and built by the government were geothermal energy-based phase change walls, but the east and west walls of the self-built house (b) built by villagers were conventional structures. From the outside to the inside, the east and west walls of the self-built house (b) were composed of a cement mortar layer (5 mm thick), an insulation layer (50 mm thick), a red clay brick layer (300 $\mathrm{mm}$ thick), and a cement mortar layer ( $5 \mathrm{~mm}$ thick). From the outside to the inside, the east and west walls of the selfbuilt house (a) were composed of a cement mortar layer (5 mm thick), an insulation layer (50 $\mathrm{mm}$ thick), a red clay brick layer (270 mm thick), a phase change layer (30 $\mathrm{mm}$ thick), and a cement mortar layer ( $5 \mathrm{~mm}$ thick); the phase change material was paraffin. The thermal conductivity of cement mortar, benzene board, red clay brick, paraffin in the solid state, and paraffin in the liquid state was $0.93 \mathrm{~W} /(\mathrm{m} \cdot \mathrm{K}), 0.05 \mathrm{~W} /(\mathrm{m} \cdot \mathrm{K}), 0.81 \mathrm{~W} /(\mathrm{m} \cdot \mathrm{K}), 0.18 \mathrm{~W} /(\mathrm{m} \cdot \mathrm{K})$, and $0.14 \mathrm{~W} /(\mathrm{m} \cdot \mathrm{K})$, respectively.

\section{Experimental methods}

The two-self built houses had the same floor area, and the structural parameters of the internal rooms are nearly the same. The basic structure of the first floor of the two houses is shown in Figure 3, including a living room, a master bedroom, a secondary bedroom, a toilet, a dining room, and a kitchen. The first floor of the self-built house had a total length of $9.6 \mathrm{~m}$, a width of $8.1 \mathrm{~m}$, and a height of $3.0 \mathrm{~m}$. The door of the living room faced south. The east and west walls of the self-built house designed by the Shangluo municipal government were the phase change walls designed in this study, and the other envelope structures were conventional. The envelope structures of the selfbuilt house built by villagers were also conventional.

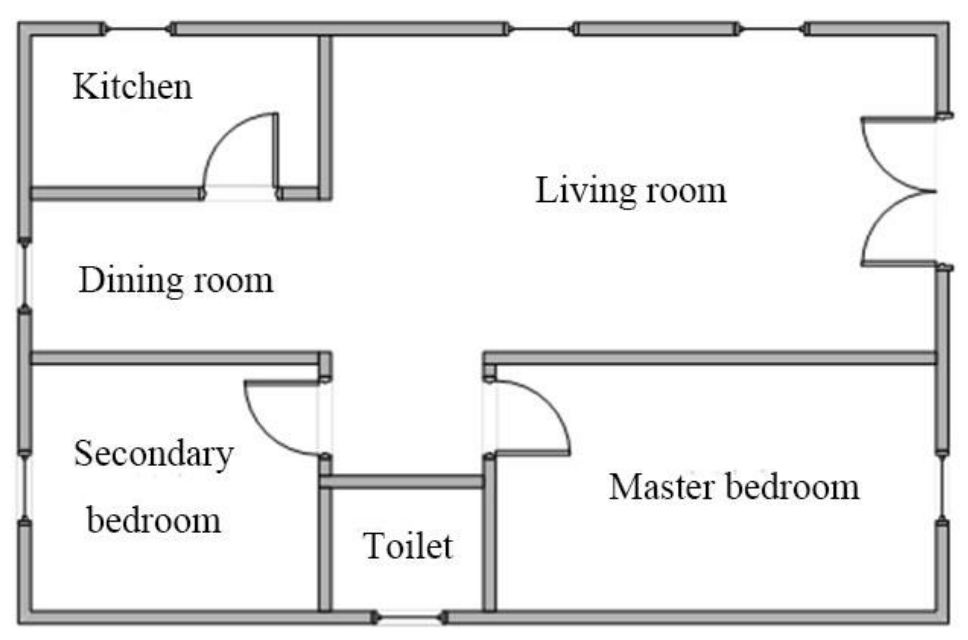

Fig. 3 - The basic structure of the first floor of two self-built houses 




Article no. 44

THE CIVIL ENGINEERING JOURNAL 2-2021

In this study, the energy-saving design of the self-built house with a phase change wall enclosure structure was analyzed. The indoor temperature stability and overall heating consumption in the self-built house with a phase change wall enclosure structure were compared with the traditional self-built house without phase change walls. The specific method is as follows. Temperature sensors were set every $0.6 \mathrm{~m}$ on the wall of the room and also set outside the room to collect the indoor and outdoor temperature changes. The resolution of the temperature sensor was $0.01{ }^{\circ} \mathrm{C}$, and the range was $-35^{\circ} \mathrm{C} \sim 80{ }^{\circ} \mathrm{C}$ The electricity consumption of the two self-built houses was detected by an electricity meter.

Test item (1.) when the self-built house with phase change walls did not turn on the water source heat pump host, the temperature sensors collected the indoor and outdoor temperature changes of the two self-built houses in two weeks, and the temperature changes of the self-built house in one day were reflected by the average temperature value at the same time of each day in two weeks.

Test item (2):the water-source heat pump host of the self-built house with phase change walls was turned on, and the two self-built houses used the central air conditioner with the same specifications and parameters to assist heating. The temperature sensors collected the indoor and outdoor temperature changes of the two self-built houses in two weeks, and the average temperature at the same time of each day in two weeks was used to reflect the temperature changes of the selfbuilt houses in one day. In addition, the accumulated power consumption of the two self-built houses in two weeks was detected by an electricity meter.

\section{Experimental results}

In order to verify the thermal insulation performance of phase change walls, the two self-built houses did not use heating equipment such as geothermal and air conditioners in the two-week experiment but used natural light as the only heat source. The final results are shown in Figure 4 . Within one day, the outdoor temperature showed a downward trend in the period of 0-8 o'clock, an upward trend in the period of 8-14 o'clock, and a downward trend again in the period of 14-24 o'clock. The minimum outdoor temperature was $6{ }^{\circ} \mathrm{C}$, and the maximum outdoor temperature was $12{ }^{\circ} \mathrm{C}$ within one day. The temperature change trends of the self-built houses designed by the villagers and the municipal government in one day were consistent with that of the outdoor. The reason for the above result was that the heating only depended on the light and was greatly affected by the external temperature. The temperature change in the self-built house built by villagers was closer to the outdoor temperature change, but the envelope had an insulation property; thus, the indoor temperature was slightly higher than the outdoor temperature. The difference between the temperature in the self-built house designed by the municipal government and the outdoor temperature was larger, and the temperature dropped more slowly in the period of temperature drop, which was because the latent heat absorbed and stored by the phase change material in the phase change wall was released at night when the indoor temperature decreased to slow down the decrease of temperature. 


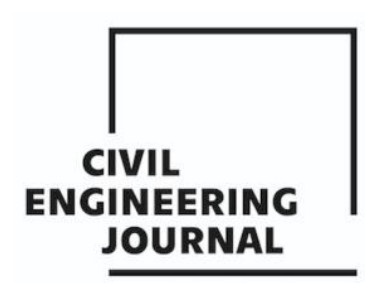

Article no. 44

THE CIVIL ENGINEERING JOURNAL 2-2021

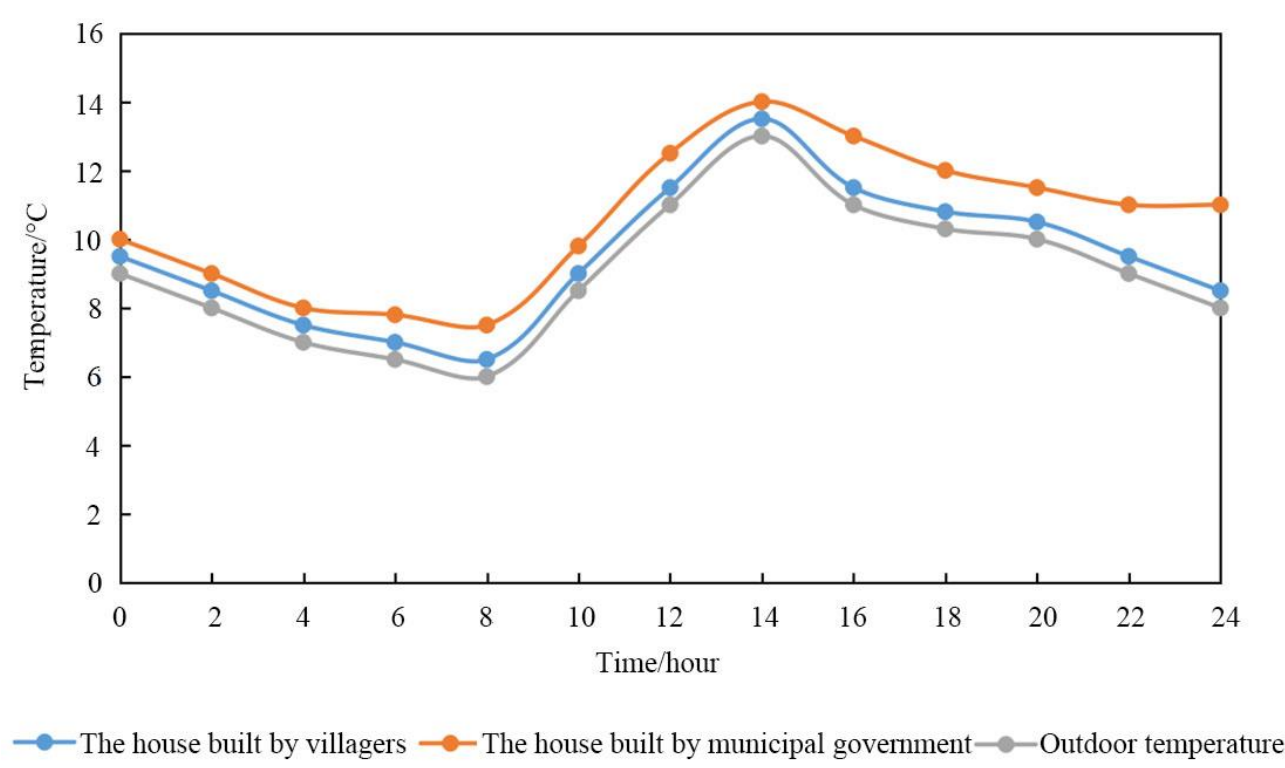

Fig. 4 - Temperature changes inside and outside two self-built houses without geothermal and air conditioner heating in one day

In order to verify the heating performance of the geothermal energy-based phase change walls, two self-built houses turned on heating equipment such as geothermal and air conditioner in the two-week experiment, and the changes of indoor and outdoor temperatures in one day are shown in Figure 5. It was seen from Figure 5 that the outdoor temperature showed a downward trend in the period of 0-8 o'clock, an upward trend in the period of 8-14 o'clock, and a downward trend in the period of 14-24 o'clock. After using the heating equipment, the indoor temperature of the two selfbuilt houses was significantly higher than the outdoor temperature, and the indoor temperature change within one day was more stable than the outside temperature change. In addition, the comparison of the indoor temperature changes of the two self-built houses showed that the self-built house with geothermal energy-based phase change walls had a higher temperature and more stable temperature changes. The reason for the above result was that the phase change material in the phase change wall had good heat storage performance, which stored the excess heat and released it to reduce the indoor temperature fluctuation and the external heat loss; the self-built house without phase change walls lost more heat because of the limited thermal insulation capacity even if there was an air conditioner for heating, resulting in significant temperature fluctuations and lower overall temperature. 


\section{$\prod_{\substack{\text { CIVIL } \\ \text { ENGINEERING } \\ \text { JOURNAL }}}$}

Article no. 44

THE CIVIL ENGINEERING JOURNAL 2-2021

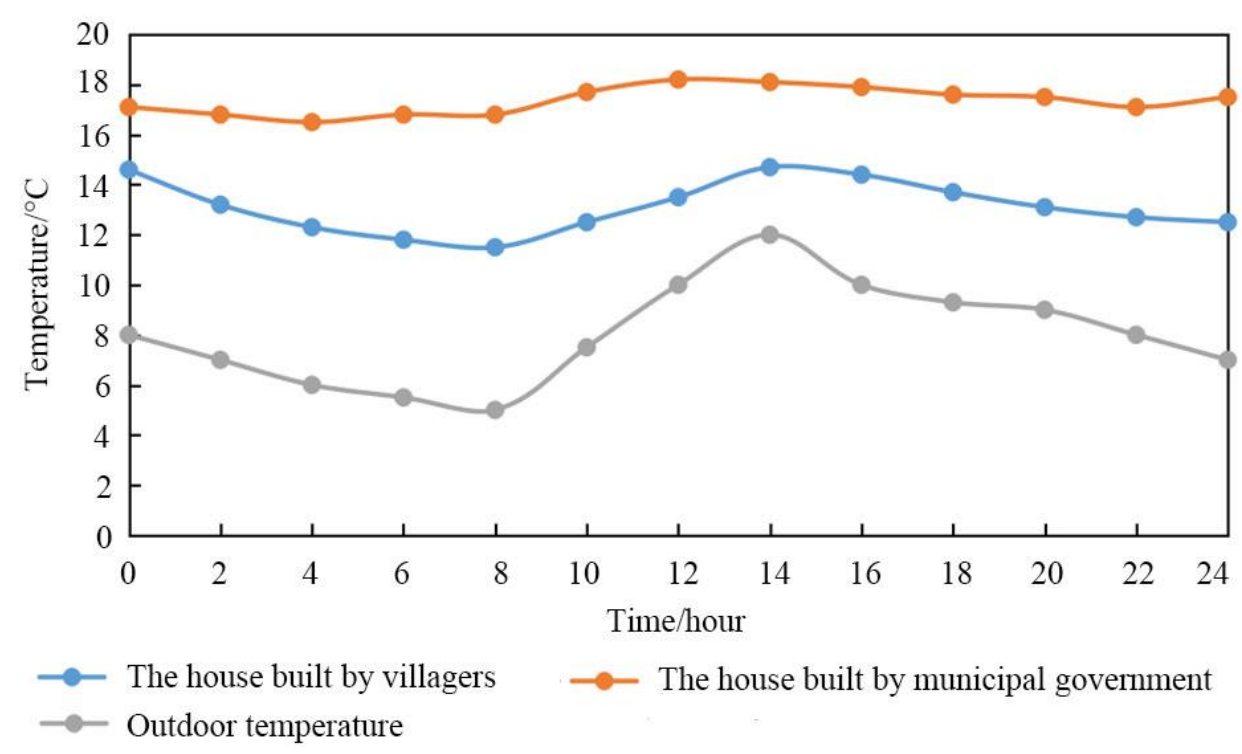

Fig. 5 - Temperature changes inside and outside two self-built houses with geothermal and air conditioner heating in one day

In order to test the heating energy-saving effect of the geothermal energy-based phase change wall as an enclosure structure, the power consumption of two self-built houses using heating equipment in two weeks was compared, and the results are shown in Figure 6 . The power consumption of self-built houses without phase change walls was $2556.4 \mathrm{kWh}$ in the two weeks, and that of the house with phase change walls was $1544.2 \mathrm{kWh}$ in the two weeks. It was seen from the comparison that the power consumption of the self-built house with phase change walls was significantly smaller than that of the self-built house without phase change walls. The reason for the above result is as follows. The phase change material of phase change walls provided better thermal insulation performance, thus reducing the frequency of indoor active heating. In addition, the phase change wall was combined with geothermal energy in this study; thus, the heat stored and released in the phase change material of the phase change wall was not only from daylight but also from geothermal energy. The power consumed in this process mainly came from the circulating pump and control equipment. The self-built house without phase change walls had poor thermal insulation performance; thus, it needed more heating to maintain the stability of indoor temperature, and the operation of the air conditioner consumed power. 


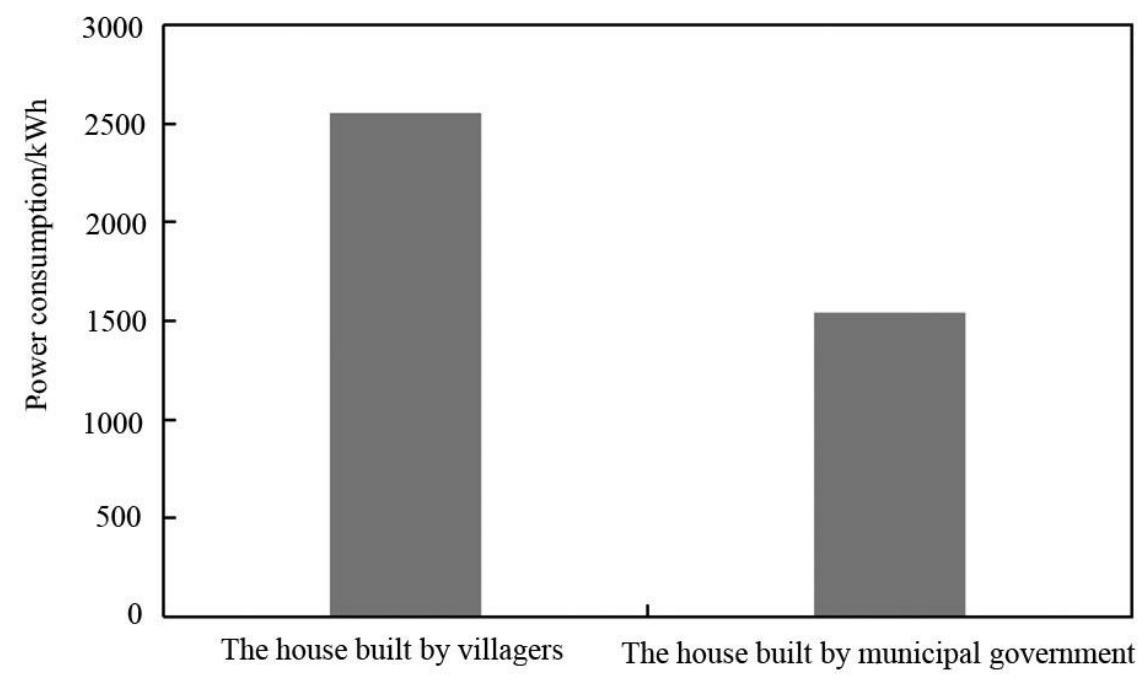

Fig. 6 - Power consumption of two self-built houses with geothermal or air conditioner heating in two weeks

\section{CONCLUSION}

This paper briefly introduced a geothermal energy-based phase change wall heating envelope and analyzed two rural self-built houses in Shangluo city, Shaanxi province, China. One self-built house was built by villagers, without phase change walls, and the other was built by a municipal government, with geothermal energy-based phase change walls. The final test results are as follows. (1) Under the premise of not using the heating equipment, the temperature change trend of the two self-built houses in one day was similar to that of the outdoor, but the indoor temperatures in the two houses were higher than the outdoor temperature, among which the indoor temperature of the self-built houses built by the municipal government was higher and changed more slowly. (2) After the heating equipment was turned on, the temperature changes of the two self-built houses tended to be stable, and the temperature of the two buildings was significantly higher than the outdoor temperature; the temperature in the self-built house built by the municipal government was higher and changed more stably. (3) After a two-week operation of the heating equipment, the power consumption of the self-built house built by the municipal government was significantly lower than that of the house built by villagers.

\section{ACKNOWLEDGMENT}

This study was supported by Shangluo City Science and Technology Plan Project 2020-Z0002 "Shangluo City Rural Ecological Agriculture Planning and Design Technology Research under the Rural Revitalization Strategy".

\section{REFERENCES}

[1] Woodson R., 2015. Radiant Floor Heating, Second Edition. JAMA: The Journal of the American Medical Association, vol. 313: 93-94

[2] Yang E., 2015. Research on Control Property of Low-Temperature Floor Radiant Heating System. Open Construction \& Building Technology Journal, vol. 9: 311-315

[3] Kim S.H., Chung K.S., Kim Y.I., 2015. Thermal Comfort Range of Radiant Floor Heating System by Residential Style. Transactions of the Korea Society of Geothermal Energy Engineers, vol. 11: 7-14 


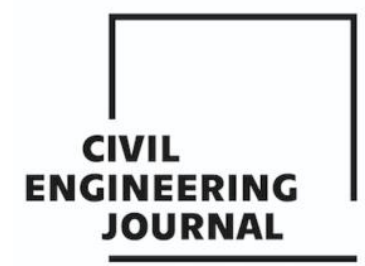

Article no. 44

THE CIVIL ENGINEERING JOURNAL 2-2021

[4] Petrichenko M., Tarasova D., Nemova D., 2015. Unsteady Temperature Condition of the Enclosure Structure. Applied Mechanics \& Materials, vol. 725-726: 57-62

[5] Feng Y., Nan Y., Zhong H., 2017. Energy-saving and thermal design of the nontransparent enclosure structure for the buildings in southern China. Journal of Civil, Architectural \& Environmental Engineering, vol. 39: 33-39

[6] Kong Q.X., Feng J., Yang C.L., 2017. Numerical Simulation of a Radiant Floor Cooling Office Based on CFD-BES Coupling and FEM. Energy Procedia, vol. 105: 3577-3583

[7] Du Y., 2014. Feasibility Analysis of Radiant Floor Cooling and Heating System Applications. Applied Mechanics and Materials, vol. 716-717: 428-430

[8] Ma H., Li C., Lu W., Zhang Z., Yu S., Du N., 2016. Experimental study of a multi-energy

complementary heating system based on a solar-groundwater heat pump unit. Applied Thermal Engineering, vol. 109: 718-726

[9] Yu B.H., Seo B.M., Moon J.W., Lee K.H., 2015. Analysis of the Part Load Ratio Characteristics and Gas Energy Consumption of a Hot Water Boiler in a Residential Building under Korean Climatic Conditions. Korean Journal of Air Conditioning \& Refrigeration Engineering, vol. 27

[10] Hong S.K., Cho S.H., 2015. The Experimental Study of the Heat Flux and Energy Consumption on Variable Flow Rate for Secondary Side of DHS. Korean Journal of Air-Conditioning and Refrigeration Engineering, vol. 27: 247-253

[11] Shaw B.H., 2018. Infection in Mental Hospitals, with Special Reference to Floor Treatment. Journal of Mental Science, vol. 69: 24-45

[12] Toyoda S., Fujiwara T., Uchida A., Ihibashi J., 2016. ESR dating of sea-floor hydrothermal barite: contribution of 228Ra to the accumulated dose. Nephron Clinical Practice, vol. 43: 201-206

[13] Barzin R., Chen J.J.J., Young B.R., Farid M.M., 2015. Application of PCM underfloor heating in combination with PCM wallboards for space heating using price based control system. Applied Energy, vol. 148: $39-48$ 